\title{
Rhoades Type Fixed Point Theorems for a Family of Hybrid Pairs of Mappings in Metrically Convex Spaces
}

\author{
LADLAY KHAN AND M. IMDAD
}

\begin{abstract}
The present paper establishes some coincidence and fixed point theorems for a sequence of hybrid type nonself mappings defined on a closed subset of a metrically convex metric spaces, which generalize some earlier results due to Rhoades [18], Ahmed and Rhoades [1] and many others. Some related results are also derived.
\end{abstract}

\section{INTRODUCTION}

The existing literature of fixed point theory contains numerous results for single as well as multi-valued self mappings, but in many applications the mapping under consideration need not always be a self mapping. In an attempt to prove results for nonself mappings in metrically convex complete metric spaces, Rhoades [17] gave sufficient conditions for such mappings to admit a fixed point by proving a fixed point theorem for certain generalized type contractions under suitable boundary conditions on the mapping. The recent literature witnessed various extentions and generalizations of this theorem of Rhoades [17], which includes Rhoades [18], Imdad and Kumar [10] and some others. For the work of this kind one can be referred to Imdad et al. [9], Ahmad and Imdad [2], Ahmad and Khan [3], Rhoades [18] and several others. Recently Ahmed and Rhoades [1] proved a result on coincidence points for two hybrid pairs of compatible continuous mappings which is essentially patterned after Ahmad and Imdad [2]

On the other hand, Huang and Cho [8] and Dhage et al. [5] proved some fixed point theorems for a sequence of set-valued mappings which generalize several results due to Itoh [11], Khan [15], Ahmad and Khan [3] and others. In this paper by combining these two ideas we prove some coincidence and fixed point theorems for a sequence of hybrid type nonself mappings satisfying certain contraction type condition which is essentially patterned after

2000 Mathematics Subject Classification. Primary 54H25; Secondary 47H10.

Key words and phrases. Metrically convex metric space; Quasi-coincidentally commuting mappings; Compatible mappings; Coincidentally idempotent. 
Rhoades [18]. Our results either partially or completely generalize earlier results due to Rhoades [18], Imdad and Kumar [10] and several others.

\section{Preliminaries}

Before proving our results, we collect the relevant definitions and results for our future use.

Let $(X, d)$ be a metric space. Then following Nadler [16], we recall

(i) $C B(X)=\{A: A$ is nonempty closed and bounded subset of $X\}$,

(ii) $C(X)=\{A: A$ is nonempty compact subset of $X\}$.

(iii) For nonempty subsets $A, B$ of $X$ and $x \in X, d(x, A)=\inf \{d(x, a)$ : $a \in A\}$ and $H(A, B)=\max [\{\sup d(a, B): a \in A\},\{\sup d(A, b): b \in B\}]$.

It is well known (cf. Kuratowski [14]) that $C B(X)$ is a metric space with the distance $H$ which is known as Hausdorff-Pompeiu metric on $X$.

The following definitions and a lemma will be frequently used in the sequel.

Definition $1([6,7])$. Let $K$ be a nonempty subset of a metric space $(X, d)$, $T: K \rightarrow X$ and $F: K \rightarrow C B(X)$. The pair $(F, T)$ is said to be weakly commuting (cf.[7]) if for every $x, y \in K$ with $x \in F y$ and $T y \in K$, we have

$$
d(T x, F T y) \leq d(T y, F y)
$$

whereas the pair $(F, T)$ is said to be compatible (cf.[6]) if for every sequence $\left\{x_{n}\right\} \subset K$, from the relation

$$
\lim _{n \rightarrow \infty} d\left(F x_{n}, T x_{n}\right)=0
$$

and $T x_{n} \in K($ for everyn $\in N)$ it follows that $\lim _{n \rightarrow \infty} d\left(T y_{n}, F T x_{n}\right)=0$, for every sequence $\left\{y_{n}\right\} \subset K$ such that $y_{n} \in F x_{n}, n \in N$.

For hybrid pairs of self type mappings these definitions were introduced by Kaneko and Sessa [13].

Definition 2 ([9]). Let $K$ be a nonempty subset of a metric space $(X, d)$, $T: K \rightarrow X$ and $F: K \rightarrow C B(X)$. The pair $(F, T)$ is said to be quasicoincidentally commuting if for all coincidence points ' $x$ ' of $(T, F), T F x \subset$ $F T x$ whenever $F x \subset K$ and $T x \in K$ for all $x \in K$.

Definition 3 ([9]). A mapping $T: K \rightarrow X$ is said to be coincidentally idempotent w.r.t mapping $F: K \rightarrow C B(X)$, if $T$ is idempotent at the coincidence points of the pair $(F, T)$.

Definition $4([4])$. A metric space $(X, d)$ is said to be metrically convex if for any $x, y \in X$ with $x \neq y$ there exists a point $z \in X, x \neq z \neq y$ such that

$$
d(x, z)+d(z, y)=d(x, y) .
$$


Lemma 1 ([4]). Let $K$ be a nonempty closed subset of a metrically convex metric space $(X, d)$. If $x \in K$ and $y \notin K$ then there exists a point $z \in \delta K$ (the boundary of $K$ ) such that $d(x, z)+d(z, y)=d(x, y)$.

\section{Results}

Our main result runs as follows.

Theorem 1. Let $(X, d)$ be a complete metrically convex metric space and $K$ a nonempty closed subset of $X$. Let $\left\{F_{n}\right\}_{n=1}^{\infty}: K \rightarrow C B(X)$ and $S, T$ : $K \rightarrow X$ satisfying:

(iv) $\delta K \subseteq S K \cap T K, F_{i}(K) \cap K \subseteq S K, F_{j}(K) \cap K \subseteq T K$,

(v) $T x \in \delta K \Rightarrow F_{i}(x) \subseteq K, S x \in \delta K \Rightarrow F_{j}(x) \subseteq K$, and

$$
\begin{gathered}
H\left(F_{i}(x), F_{j}(y)\right) \leq h \max \left\{\frac{1}{a} d(T x, S y), d\left(T x, F_{i}(x)\right), d\left(S y, F_{j}(y)\right),\right. \\
\left.\frac{1}{a+h}\left(d\left(T x, F_{j}(y)\right)+d\left(S y, F_{i}(x)\right)\right)\right\},
\end{gathered}
$$

where $i=2 n-1, j=2 n,(n \in N), i \neq j$ for all $x, y \in K$ with $x \neq y$, where $0<h<\frac{-1+\sqrt{5}}{2}, a \geq 1+\frac{2 h^{2}}{1+h}$,

(vi) $\left(F_{i}, T\right)$ and $\left(F_{j}, S\right)$ are compatible pairs,

(vii) $\left\{F_{n}\right\}, S$ and $T$ are continuous on $K$.

Then $\left\{F_{n}\right\}, S$ and $T$ have a point of common coincidence.

Proof. Firstly, we proceed to construct two sequences $\left\{x_{n}\right\}$ and $\left\{y_{n}\right\}$ in the following way. Assume $\alpha=h(1+h)$. Let $x \in \delta K$. Then (due to $\delta K \subseteq T K$ ) there exists a point $x_{0} \in K$ such that $x=T x_{0}$. From the implication $T x \in \delta K$, implies $F_{1}\left(x_{0}\right) \subseteq F_{1}(K) \cap K \subseteq S K$, let $x_{1} \in K$ be such that $y_{1}=S x_{1} \in F_{1}\left(x_{0}\right) \subseteq K$. Since $y_{1} \in F_{1}\left(x_{0}\right)$, there exists a point $y_{2} \in F_{2}\left(x_{1}\right)$ such that

$$
d\left(y_{1}, y_{2}\right) \leq H\left(F_{1}\left(x_{0}\right), F_{2}\left(x_{1}\right)\right)+\alpha .
$$

Suppose $y_{2} \in K$. Then $y_{2} \in F_{2}(K) \cap K \subseteq T K$, implies that there exists a point $x_{2} \in K$ such that $y_{2}=T x_{2}$. Otherwise, if $y_{2} \notin K$ then there exists a point $p \in \delta K$ such that

$$
d\left(S x_{1}, p\right)+d\left(p, y_{2}\right)=d\left(S x_{1}, y_{2}\right) .
$$

Since $p \in \delta K \subseteq T K$, there exists a point $x_{2} \in K$ with $p=T x_{2}$ so that

$$
d\left(S x_{1}, T x_{2}\right)+d\left(T x_{2}, y_{2}\right)=d\left(S x_{1}, y_{2}\right) .
$$

Let $y_{3} \in F_{3}\left(x_{2}\right)$ be such that $d\left(y_{2}, y_{3}\right) \leq H\left(F_{2}\left(x_{1}\right), F_{3}\left(x_{2}\right)\right)+\alpha^{2}$

Thus, repeating the foregoing arguments, we obtain two sequences $\left\{x_{n}\right\}$ and $\left\{y_{n}\right\}$ such that 
(viii) $y_{2 n} \in F_{2 n}\left(x_{2 n-1}\right)$ for all $n \in N$, $y_{2 n+1} \in F_{2 n+1}\left(x_{2 n}\right)$ for all $n \in N_{0}=N \cup\{0\}$,

(ix) $y_{2 n} \in K \Rightarrow y_{2 n}=T x_{2 n}$ or $y_{2 n} \notin K \Rightarrow T x_{2 n} \in \delta K$ and $d\left(S x_{2 n-1}, T x_{2 n}\right)+d\left(T x_{2 n}, y_{2 n}\right)=d\left(S x_{2 n-1}, y_{2 n}\right)$,

(x) $y_{2 n+1} \in K \Rightarrow y_{2 n+1}=S x_{2 n+1}$ or $y_{2 n+1} \notin K \Rightarrow S x_{2 n+1} \in \delta K$ and $d\left(T x_{2 n}, S x_{2 n+1}\right)+d\left(S x_{2 n+1}, y_{2 n+1}\right)=d\left(T x_{2 n}, y_{2 n+1}\right)$

(xi) $d\left(y_{2 n-1}, y_{2 n}\right) \leq H\left(F_{2 n-1}\left(x_{2 n-2}\right), F_{2 n}\left(x_{2 n-1}\right)\right)+\alpha^{2 n-1}$ $d\left(y_{2 n}, y_{2 n+1}\right) \leq H\left(F_{2 n}\left(x_{2 n-1}\right), F_{2 n+1}\left(x_{2 n}\right)\right)+\alpha^{2 n}$.

We denote

$$
\begin{aligned}
& P_{\circ}=\left\{T x_{2 i} \in\left\{T x_{2 n}\right\}: T x_{2 i}=y_{2 i}\right\}, P_{1}=\left\{T x_{2 i} \in\left\{T x_{2 n}\right\}: T x_{2 i} \neq y_{2 i}\right\}, \\
& Q_{\circ}=\left\{S x_{2 i+1} \in\left\{S x_{2 n+1}\right\}: S x_{2 i+1}=y_{2 i+1}\right\} \quad \text { and } \\
& Q_{1}=\left\{S x_{2 i+1} \in\left\{S x_{2 n+1}\right\}: S x_{2 i+1} \neq y_{2 i+1}\right\} .
\end{aligned}
$$

One can note that $\left(T x_{2 n}, S x_{2 n+1}\right) \notin P_{1} \times Q_{1}$ and $\left(S x_{2 n-1}, T x_{2 n}\right) \notin Q_{1} \times P_{1}$.

Now, we distinguish the following three cases.

Case 1. If $\left(T x_{2 n}, S x_{2 n+1}\right) \in P_{\circ} \times Q_{\circ}$, then

$$
\begin{aligned}
& d\left(T x_{2 n}, S x_{2 n+1}\right) \leq H\left(F_{2 n+1}\left(x_{2 n}\right), F_{2 n}\left(x_{2 n-1}\right)\right)+\alpha^{2 n} \\
\leq & h \max \left\{\frac{1}{a} d\left(T x_{2 n}, S x_{2 n-1}\right), d\left(T x_{2 n}, F_{2 n+1}\left(x_{2 n}\right)\right), d\left(S x_{2 n-1}, F_{2 n}\left(x_{2 n-1}\right)\right),\right. \\
& \left.\frac{1}{a+h}\left(d\left(T x_{2 n}, F_{2 n}\left(x_{2 n-1}\right)\right)+d\left(S x_{2 n-1}, F_{2 n+1}\left(x_{2 n}\right)\right)\right)\right\}+\alpha^{2 n} \\
= & h \max \left\{\frac{1}{a} d\left(T x_{2 n}, S x_{2 n-1}\right), d\left(T x_{2 n}, S x_{2 n+1}\right), d\left(S x_{2 n-1}, T x_{2 n}\right),\right. \\
\leq & \max \left\{h d\left(T x_{2 n}, S x_{2 n-1}\right)+\alpha^{2 n}, \frac{\alpha^{2 n}}{1-h},\right. \\
\qquad & \left.\frac{1}{a}\left(h d\left(S x_{2 n-1}, T x_{2 n}\right)+\alpha^{2 n}(a+h)\right)\right\} \\
\leq & h d\left(T x_{2 n}, S x_{2 n-1}\right)+\max \left\{\frac{1}{1-h}, \frac{a+h}{a}\right\} \alpha^{2 n} \\
\leq & h d\left(T x_{2 n}, S x_{2 n-1}\right)+\frac{\alpha^{2 n}}{1-h} .
\end{aligned}
$$

Similarly, if $\left(S x_{2 n-1}, T x_{2 n}\right) \in Q_{\circ} \times P_{\circ}$, then

$$
d\left(S x_{2 n-1}, T x_{2 n}\right) \leq h d\left(T x_{2 n-2}, S x_{2 n-1}\right)+\frac{\alpha^{2 n-1}}{1-h} .
$$

Case 2. If $\left(T x_{2 n}, S x_{2 n+1}\right) \in P_{\circ} \times Q_{1}$, then

$$
d\left(T x_{2 n}, S x_{2 n+1}\right)+d\left(S x_{2 n+1}, y_{2 n+1}\right)=d\left(T x_{2 n}, y_{2 n+1}\right)
$$


which in turn yields $d\left(T x_{2 n}, S x_{2 n+1}\right) \leq d\left(T x_{2 n}, y_{2 n+1}\right)=d\left(y_{2 n}, y_{2 n+1}\right)$, and hence $d\left(T x_{2 n}, S x_{2 n+1}\right) \leq d\left(y_{2 n}, y_{2 n+1}\right) \leq H\left(F_{2 n+1}\left(x_{2 n}\right), F_{2 n}\left(x_{2 n-1}\right)\right)+\alpha^{2 n}$.

Now, proceeding as in Case 1, we have

$$
d\left(T x_{2 n}, S x_{2 n+1}\right) \leq h d\left(T x_{2 n}, S x_{2 n-1}\right)+\frac{\alpha^{2 n}}{1-h} .
$$

In case $\left(S x_{2 n-1}, T x_{2 n}\right) \in Q_{1} \times P_{\circ}$ then as earlier, one also obtains

$$
d\left(S x_{2 n-1}, T x_{2 n}\right) \leq h d\left(S x_{2 n-1}, T x_{2 n-2}\right)+\frac{\alpha^{2 n-1}}{1-h} .
$$

Case 3. If $\left(T x_{2 n}, S x_{2 n+1}\right) \in P_{1} \times Q_{\circ}$ then $S x_{2 n-1}=y_{2 n-1}$. Proceeding as in Case 1, one gets

$$
\begin{aligned}
& d\left(T x_{2 n}, S x_{2 n+1}\right)=d\left(T x_{2 n}, y_{2 n+1}\right) \\
\leq & d\left(T x_{2 n}, y_{2 n}\right)+d\left(y_{2 n}, y_{2 n+1}\right) \\
\leq & d\left(S x_{2 n-1}, y_{2 n}\right)+H\left(F_{2 n+1}\left(x_{2 n}\right), F_{2 n}\left(x_{2 n-1}\right)\right)+\alpha^{2 n} \\
\leq & d\left(S x_{2 n-1}, y_{2 n}\right) \\
& +h \max \left\{\frac{1}{a} d\left(T x_{2 n}, S x_{2 n-1}\right), d\left(T x_{2 n}, S x_{2 n+1}\right), d\left(S x_{2 n-1}, T x_{2 n}\right),\right. \\
& \left.\quad \frac{1}{a+h}\left(d\left(T x_{2 n}, F_{2 n}\left(x_{2 n-1}\right)\right)+d\left(S x_{2 n-1}, F_{2 n+1}\left(x_{2 n}\right)\right)\right)\right\}+\alpha^{2 n} \\
\leq & d\left(S x_{2 n-1}, y_{2 n}\right) \\
& +h \max \left\{\frac{1}{a} d\left(T x_{2 n}, S x_{2 n-1}\right), d\left(T x_{2 n}, S x_{2 n+1}\right), d\left(S x_{2 n-1}, T x_{2 n}\right),\right. \\
\leq & \left.\left.\quad \frac{1}{a+h}\left(d\left(T x_{2 n}, F_{2 n}\left(x_{2 n-1}\right)\right)+d\left(S x_{2 n-1}, S x_{2 n+1}\right)\right)\right\}+\alpha^{2 n}\right) \\
& +h \max \left\{\frac{1}{a} d\left(y_{2 n}, S x_{2 n-1}\right), d\left(T x_{2 n}, S x_{2 n+1}\right), d\left(S x_{2 n-1}, y_{2 n}\right),\right. \\
& \left.\quad \frac{1}{a+h}\left(d\left(T x_{2 n}, y_{2 n}\right)+d\left(S x_{2 n-1}, S x_{2 n+1}\right)\right)\right\}+\alpha^{2 n} \\
\leq & \max \left\{(1+h) d\left(y_{2 n}, S x_{2 n-1}\right)+\alpha^{2 n},(1+h) d\left(y_{2 n}, S x_{2 n-1}\right)+\frac{\alpha^{2 n}}{1-h},\right. \\
\leq & \left.\frac{1}{a}\left(h d\left(S x_{2 n-1}, y_{2 n}\right)+(a+h) \alpha^{2 n}\right)\right\} \\
\leq & h(1+h) d\left(y_{2 n}, S x_{2 n-1}\right)+\frac{\alpha^{2 n}}{1-h} \\
& \left.h x_{2 n-2}, S x_{2 n-1}\right)+h \frac{\alpha^{2 n-1}}{1-h}+\frac{\alpha^{2 n}}{1-h} .
\end{aligned}
$$


Thus if put $z_{2 n}=T x_{2 n}, z_{2 n+1}=S x_{2 n+1}$, then one obtains

$$
d\left(z_{n}, z_{n+1}\right) \leq \begin{cases}h d\left(z_{n-1}, z_{n}\right)+\frac{\alpha^{n}}{1-h}, & \text { or } \\ h(1+h) d\left(z_{n-2}, z_{n-1}\right)+\frac{h \alpha^{n-1}}{1-h}+\frac{\alpha^{n}}{1-h} . & \end{cases}
$$

Now on the lines of Itoh [11] it can be shown that $\left\{z_{n}\right\}$ is Cauchy and there exists at least one subsequence $\left\{T x_{2 n_{k}}\right\}$ or $\left\{S x_{2 n_{k}+1}\right\}$ which is contained in $P_{\circ}$ or $Q_{\circ}$ respectively. Consequently the subsequence $\left\{T x_{2 n_{k}}\right\}$ which is contained in $P_{\circ}$ for each $k \in N$, converges to $z$. Using compatibility of $\left(F_{j}, S\right)$, we have

$$
\lim _{k \rightarrow \infty} d\left(S x_{2 n_{k}-1}, F_{j}\left(x_{2 n_{k}-1}\right)\right)=0 \quad \text { for any even integer } j \in N,
$$

which implies that $\lim _{k \rightarrow \infty} d\left(S T x_{2 n_{k}}, F_{j}\left(S x_{2 n_{k}-1}\right)\right)=0$.

Using the continuity of $S$ and $F_{j}$, one obtains $S z \in F_{j}(z)$, for any even integer $j \in N$. Similarly the continuity of $T$ and $F_{i}$ implies $T z \in F_{i}(z)$, for any odd integer $i \in N$. Now

$$
\begin{aligned}
d(T z, S z) \leq & H\left(F_{i}(z), F_{j}(z)\right) \\
\leq & h \max \left\{\frac{1}{a} d(T z, S z), d\left(T z, F_{i}(z)\right), d\left(S z, F_{j}(z)\right),\right. \\
& \left.\frac{1}{a+h}\left(d\left(T z, F_{j}(z)\right)+d\left(S z, F_{i}(z)\right)\right)\right\} \\
\leq & h \max \left\{\frac{1}{a} d(T z, S z), 0,0, \frac{2}{a+h} d(T z, S z)\right\} \\
\leq & \max \left\{\frac{h}{a}, \frac{2 h}{a+h}\right\} d(T z, S z),
\end{aligned}
$$

yielding thereby $T z=S z$, which shows that $z$ is a common coincidence point of $\left\{F_{n}\right\}, S$ and $T$.

Remark 1. By setting $F_{i}=F$ (for any odd integer $i \in N$ ) and $F_{j}=G$ (for any even integer $j \in N$ ) in Theorem 1 , one deduces a result due to Ahmed and Rhoades [1].

In the next theorem we utilize the closedness of $T K$ and $S K$ so as to relax the continuity requirements besides limiting the commutativity to points of coincidence.

Theorem 2. Let $(X, d)$ be a complete metrically convex metric space and $K$ a nonempty closed subset of $X$. Let $\left\{F_{n}\right\}_{n=1}^{\infty}: K \rightarrow C B(X)$ and $S, T$ : $K \rightarrow X$ satisfying (1), (iv) and (v). Suppose that

(xii) $T K$ and $S K$ are closed subspaces of $X$. Then

(a) $\left(F_{i}, T\right)$ has a point of coincidence,

(b) $\left(F_{j}, S\right)$ has a point of coincidence. 
Moreover, $\left(F_{i}, T\right)$ has a common fixed point if $T$ is quasi-coincidentally commuting and coincidentally idempotent w.r.t $F_{i}$, whereas $\left(F_{j}, S\right)$ has a common fixed point provided $S$ is quasi-coincidentally commuting and coincidentally idempotent w.r.t $F_{j}$.

Proof. On the lines of the proof of the Theorem 1, one assumes that there exists a subsequence $\left\{T x_{2 n_{k}}\right\}$ which is contained in $P_{\circ}$ and $T K$ as well as $S K$ are closed subspaces of $X$. Since $\left\{T x_{2 n_{k}}\right\}$ is Cauchy in $T K$, it converges to a point $u \in T K$. Let $v \in T^{-1} u$, then $T v=u$. Since $\left\{S x_{2 n_{k}+1}\right\}$ is a subsequence of Cauchy sequence, $\left\{S x_{2 n_{k}+1}\right\}$ converges to $u$ as well. Using (1), one can write

$$
\begin{aligned}
& d\left(F_{i}(v), T x_{2 n_{k}}\right) \leq H\left(F_{i}(v), F_{j}\left(x_{2 n_{k}-1}\right)\right) \\
& \leq h \max \left\{\frac{1}{a} d\left(T v, S x_{2 n_{k}-1}\right), d\left(S x_{2 n_{k}-1}, F_{j}\left(x_{2 n_{k}-1}\right)\right), d\left(T v, F_{i}(v)\right),\right. \\
&\left.\frac{1}{a+h}\left(d\left(T v, F_{j}\left(x_{2 n_{k}-1}\right)\right)+d\left(S x_{2 n_{k}-1}, F_{i}(v)\right)\right)\right\}
\end{aligned}
$$

which on letting $k \rightarrow \infty$, reduces to

$$
\begin{aligned}
d\left(F_{i}(v), u\right) & \leq h \max \left\{0,0, d\left(u, F_{i}(v)\right), \frac{1}{a+h}\left(0+d\left(F_{i}(v), u\right)\right)\right\} \\
& \leq \max \left\{h, \frac{h}{a+h}\right\} d\left(u, F_{i}(v)\right)
\end{aligned}
$$

yielding thereby $u \in F_{i}(v)$, which implies that $u=T v \in F_{i}(v)$ as $F_{i}(v)$ is closed.

Since Cauchy sequence $\left\{T x_{2 n}\right\}$ converges to $u \in K$ and $u \in F_{i}(v), u \in$ $F_{i}(K) \cap K \subseteq S K$, there exists $w \in K$ such that $S w=u$. Again using (1), one gets

$$
\begin{aligned}
d\left(S w, F_{j}(w)\right)= & d\left(T v, F_{j}(w)\right) \leq H\left(F_{i}(v), F_{j}(w)\right) \\
\leq & h \max \left\{\frac{1}{a} d(T v, S w), d\left(T v, F_{i}(v)\right), d\left(S w, F_{j}(w)\right),\right. \\
& \left.\frac{1}{a+h}\left(d\left(T v, F_{j}(w)\right)+d\left(S w, F_{i}(v)\right)\right)\right\} \\
\leq & \max \left\{h, \frac{h}{a+h}\right\} d\left(S w, F_{j}(w)\right)
\end{aligned}
$$

implying thereby $S w \in F_{j}(w)$, that is $w$ is a coincidence point of $\left(S, F_{j}\right)$.

If one assumes that there exists a subsequence $\left\{S x_{2 n_{k}+1}\right\}$ contained in $Q$ 。 with $T K$ as well as $S K$ are closed subspaces of $X$, then noting that $\left\{S x_{2 n_{k}+1}\right\}$ is Cauchy in $S K$, the foregoing arguments establish that $T v \in$ $F_{i}(v)$ and $S w \in F_{j}(w)$.

Since $v$ is a coincidence point of $\left(F_{i}, T\right)$ therefore using quasi-coincidentally commuting as well as coincidentally idempotent property of $T$ w.r.t $F_{i}$, one 
can have

$$
T v \in F_{i}(v) \text { and } u=T v \Rightarrow T u=T T v=T v=u,
$$

therefore $u=T u=T T v \in T F_{i}(v) \subset F_{i}(T v)=F_{i}(u)$, which shows that $u$ is the common fixed point of $\left(F_{i}, T\right)$. Similarly using the quasi-coincidentally commuting as well as coincidentally idempotent property of $S$ w.r.t $F_{j}$, one can show that $\left(F_{j}, S\right)$ has a common fixed point as well.

Remark 2. By setting $F_{n}=F($ for $n \in N)$ and $S=T=I_{K}$ in Theorem 2 , one deduces a result due to Rhoades [18].

Remark 3. A fixed point theorem similar to Theorem 3.2 can also be outlined in respect of Theorem 2 .

Finally, we prove a theorem when "closedness of $K$ " is replaced by "compactness of $K^{\prime \prime}$.

Theorem 3. Let $(X, d)$ be a complete metrically convex metric space and $K$ a nonempty compact subset of $X$. Let $\left\{F_{n}\right\}_{n=1}^{\infty}: K \rightarrow C B(X)$ and $T: K \rightarrow X$ satisfying:

(xiii) $\delta K \subseteq T K,\left(F_{i}(K) \cup F_{j}(K)\right) \cap K \subseteq T K$,

(xiv) $T x \in \delta K \Rightarrow F_{i}(x) \cup F_{j}(x) \subseteq K$ with

$H\left(F_{i}(x), F_{j}(y)\right)<M(x, y)$ when $M(x, y)>0$, for all $x, y \in K$ where

$$
\begin{array}{r}
M(x, y)=h \max \left\{\frac{1}{a} d(T x, T y), d\left(T x, F_{i}(x)\right), d\left(T y, F_{j}(y)\right),\right. \\
\left.\frac{1}{a+h}\left(d\left(T x, F_{j}(y)\right)+d\left(T y, F_{i}(x)\right)\right)\right\}
\end{array}
$$

where $i=2 n-1, j=2 n,(n \in N), i \neq j$ for all $x, y \in K$ with $x \neq y$, where $0 \leq h \leq \frac{-1+\sqrt{5}}{2}, a \geq 1+\frac{2 h^{2}}{1+h}$.

If $T$ is compatible with $\left\{F_{n}\right\}(n \in N)$ then $\left\{F_{n}\right\}$ and $T$ have a common point of coincidence, provided all involves maps are continuous.

Proof. We assert that $M(x, y)=0$ for some $x, y \in K$. Otherwise $M(x, y) \neq$ 0 , for any $x, y \in K$ implies that

$$
f(x, y)=\frac{H\left(F_{i}(x), F_{j}(y)\right)}{M(x, y)}
$$

is continuous and satisfies $f(x, y)<1$ for all $(x, y) \in K \times K$. Since $K \times K$ is compact, there exists $(u, v) \in K \times K$ such that $f(x, y) \leq f(u, v)=c<1$ for $x, y \in K$, which in turn yields $H\left(F_{i}(x), F_{j}(y)\right) \leq c M(x, y)$ for $x, y \in K$ and $0<c<1$. Therefore using (2), one obtains

$$
\max \left\{\frac{1}{1-c h}, \frac{a+h}{a+h(1-c)}\right\}<1 .
$$


Now, by Theorem 1 (with restriction $S=T$, we get $T z \in F_{i}(z) \cap F_{j}(z)$ for some $z \in K$ and one concludes $M(z, z)=0$ contradicting the facts that $M(x, y)>0$. Therefore $M(x, y)=0$ for some $x, y \in K$ which implies $T x \in F_{i}(x)$ for any odd integer $i \in N$ and $T x=T y \in F_{j}(y)$ for any even integer $j \in N$. If $M(x, x)=0$ then $T x \in F_{j}(x)$ for any even integer $j \in N$ and if $M(x, x) \neq 0$ then using (2), one infers that $d\left(T x, F_{j}(x)\right) \leq 0$ yielding thereby $T x \in F_{j}(x)$ for any even integer $j \in N$. Similarly in either of the cases $M(y, y)=0$ or $M(y, y)>0$, one concludes that $T y \in F_{i}(y)$ for any odd integer $i \in N$. Thus we have shown that $\left\{F_{n}\right\}$ and $T$ have a common point of coincidence. This completes the proof.

While proving Theorem 3 the following question remains unresolved: Does Theorem 3.3 hold for $\left\{F_{n}\right\}, S$ and $T$ instead of $\left\{F_{n}\right\}$ and $T$ ?

Acknowledgment. Both the authors are grateful to an anonymous referee for their fruitful suggestions.

\section{REFERENCES}

[1] M. A. Ahmed and B. E. Rhoades, Some common fixed point theorems for compatible mappings, Indian J. Pure Appl. Math. 32(8)(2001), 1247-1254.

[2] A. Ahmad and M. Imdad, Some common fixed point theorems for mappings and multi-valued mappings, J. Math. Anal. Appl. 218(1998), 546-560.

[3] A. Ahmad and A. R. Khan, Some common fixed point theorems for nonlinear hybrid contractions, J. Math. Anal. Appl. 213(1997), 275-286.

[4] N. A. Assad and W. A. Kirk, Fixed point theorems for set-valued mappings of contractive type, Pacific J. Math. 43(3)(1972), 553-562.

[5] B. C. Dhage, U. P. Dolhare and A. Petrusel, Some common fixed point theorems for sequences of nonself multi-valued operators in metrically convex metric spaces, Fixed Point Theory. 4(2)(2003), 143-158.

[6] O. Hadžic̀, On coincidence points in convex metric spaces, Univ. u Novom Sadu. Zb. Rad. Prirod. Mat. Fak. Ser. Mat. 19(2)(1986), 233-240.

[7] O. Hadžic̀ and Lj. Gajic, Coincidence points for set-valued mappings in convex metric spaces, Univ. u Novom Sadu. Zb. Rad. Prirod. Mat. Fak. Ser. Mat. 16(1) (1986), $13-25$.

[8] N. J. Huang and Y. J. Cho, Common fixed point theorems for a sequence of set-valued mappings, Korean J. Math. Sci. 4(1997), 1-10.

[9] M. Imdad, A. Ahmad and S. Kumar, On nonlinear nonself hybrid contractions, Radovi Mat. 10(2001), 243-254.

[10] M. Imdad and S. Kumar, Rhoades type fixed point theorems for a pair of nonself mappings, Comp. Math. Appl. 46(2003), 919-927.

[11] S. Itoh, Multi-valued generalized contractions and fixed point theorems, Comment. Math. Univ. Carolinae, 18(1977), 247-258.

[12] S. Itoh and W. Takahashi, Single valued mappings multi-valued mappings and fixed point theorems, J. Math. Anal. Appl. 59(1977), 514-521. 
[13] H. Kaneko and S. Sessa, Fixed point theorems for compatible multi-valued and single valued mappings, Internat. J. Math. Math. Sci. 12(2)(1989), 257-262.

[14] K. Kuratowski, Topology, Academic Press. Vol(I) 1966.

[15] M. S. Khan, Common fixed point theorems for multivalued mappings, Pacific J. Math. 95(2)(1981), 337-347.

[16] S. B. Nadler, Multi-valued contraction mappings, Pacific J. Math. 30(2)(1969), 475488.

[17] B. E. Rhoades, A fixed point theorem for some nonself mappings, Math. Japon. 23(4)(1978), 457-459.

[18] B. E. Rhoades, A fixed point theorem for nonself set-valued mappings, Internat. J. Math. Math. Sci. 20(1)(1997), 9-12.

\section{LADLAY KHAN}

Department of Mathematics

Mewat Engineering college (Wakf)

Palla, Nuh, Mewat 122107

INDIA

E-mail address: k_ladlay@yahoo.com

\section{IMDAD}

Department of Mathematics

Aligarh Muslim University

Aligarh 202002

INDIA

E-mail address: mhimdad@yahoo.co.in 